\title{
Analysis of Investment Style Changing: The U.S. Stock Market in Apparel Industry During Covid-19
}

\author{
Xinyu Jiang ${ }^{\dagger 1}$, Zhuoer $\mathrm{Li}^{\dagger 2}$, Chenrui $\mathrm{Xu}^{\dagger 3}$ \\ ${ }^{1}$ School of Science, Xi'an Jiaotong-liverpool University (XJTLU), Suzhou, China, Xinyu.Jiang19@student.xjtlu.edu.cn \\ ${ }^{2}$ School of Mathematics and Statistics University of Sheffield Sheffield, UK, zli192@ sheffield.ac.uk \\ ${ }^{3}$ School of Mathematics University of Edinburgh Edinburgh, UK, C.Xu-43@sms.ed.ac.uk \\ These authors contributed equally.
}

\begin{abstract}
The impact that COVID-19 brought to the financial market all over the world was huge, especially on the stock market. Not only the stock prices became unpredictable, but also the stock traders' decisions started to change in an unexpected way. This paper focuses on analyzing the U.S. stock market of clothing industry by using Fama-French five factor model, and comparing Fama-French five factor model with other competing asset pricing models, for example Capital Asset Pricing Model. Also, the differences and changes that stock traders makes are discussed in the U.S. stock market after the pandemic of COVID-19. The result shows that the thats value of SMB (Small Minus Big), HML(High Minus Low) and CMA (Conservative Minus Aggressive) becomes significant after the pandemic. Therefore, it means that the companies with small-scall, value characteristic, and aggressive investment style are more able to be more favored by the investors during this pandemic.
\end{abstract}

Keywords-component, Fama-French Model, Apparel Industry, Covid-19, U.S. Stock Market.

\section{INTRODUCTION}

The uncertainty and unpredictability form the risk in the financial market. The asset pricing model demonstrates that how investors optimally allocate their wealth among numerous risky assets and how they determine the equilibrium price of various risky assets in the financial market. Considering the difference between people's expectation and the fluctuation of asset price, the asset pricing model equates the future returns with the asset prices. The most significant issue in the asset pricing theory is to maximize the exposure of random variations that represent the overall movement of risk in the entire financial system. The asset pricing model explores the expected rate of return of various securities and the stock portfolios with different beta value levels, which reflects the equilibrium relationship between the risk and expected returns on financial or real assets. The asset pricing model uses coefficient beta to clearly indicate the expected return and the systematic risk when investing in securities. This model has experienced enormous changes throughout time. Taking COVID-19 as an example, the spread of the virus affected more than 210 countries and territories around the world. The outbreak of COVID-19 pandemic has taken a heavy toll on the global economy development. COVID-19 has caused the disruption of supply chain as well as a sharp decline in the international trade and commerce, thus ultimately giving rise to the inevitable economic crisis. Additionally, COVID-19 has impaired the finance sector by causing a mild economic depression, such as the rise in unemployment and the decrease in GDP growth. Overall, the economic recovery after COVID-19 seems shaky and sluggish. On the other hand, the COVID-19 epidemic, to some extent, facilitates the amelioration and reformation of the asset pricing model in the financial market. The asset pricing model reveals how mode of production in enterprises or companies changes after the COVID-19 epidemic. Simultaneously, these changes offer guidance and reference for investors when electing securities in the financial market.

Afterwards, scholars conducted studies in many countries. Connor and Sehgal studied the Fama-French three-factor stock return model in India. They found the evidence of the market, size, and mark-to-market factors that were prevalent in Indian stock returns. The research figured out that the average cross-sectional return was explained by the impact on these three factors, not just by the market factors. It found mixed evidence regarding 
parallel markets, size, and book-market value factors. It could not find any reliable connection between the common risk factors of returns and the stock returns. Overall, the empirical results were quite consistent with the Fama French three-factor model [1]. Faff studied a simple test of the Fama and French model by using daily data. It showed the useful proxies for the Fama and French factors could be readily constructed from 'off the shelf' style index data. This research chose the generalized method of moments (GMM) to test the Fama and French three factor model and used the data of 24 Australian industry portfolios from Datastream International. Overall, it came up to a question that, did this wave of doubt over the size premium and more generally over the Fama and French model herald that a new 'twist' in the asset pricing saga is nigh? But for now, only the time will tell [2]. Trimech et al studied the application of Multiscale Fama-French model in French market. It discussed a multiscale pricing model for the French stock market by combining wavelet analysis and Fama-French three-factor model. By doing the research, the obtained results showed that as the wavelet scale increased, the explanatory power of the Fama-French three-factor model was enhanced. In addition, the relationship between the portfolio returns and the risk factors (ie, market, size, and value factors) depended, to a large extent, on the time span under consideration [3]. Czapkiewicz and Skalna studied the CAPM and FamaFrench Models in Poland. They studied the ability of the Fama-French three-factor model to explain the crosssectional difference in the asset returns from December 2002 to January 2010. The research was conducted on the Warsaw Stock Exchange (WSE). Financial data came from CEDULA1. CEDULA1 is a daily official announcement that provides information from WSE. The system risk and the risk premium were estimated using the Generalized Method of Moments (GMM), which took into account the autocorrelation and heteroscedasticity in the time series. The test proposed by MacKinlay and Richardson executed the process of testing whether the intercepts were collectively zero. The results indicated that three factor models could be used to explain stock returns: the excess return relative to the market (market factor), the difference between the returns of portfolios with large and small capital (size factor, SMB), and the difference between the two, as well as the high and low book value versus market value (HML) portfolio returns [4].

Moreover, Chiah et al studied an empirical investigation of the Fama-French five-factor model in Australia. It compared and evaluated the performance of the Fama-French five-factor and other competing asset pricing models, such as CAPM and three factor models, in pricing Australian equities. Also, it investigated whether the five-factor could explain more asset pricing anomalies than other competing asset pricing models by using the primary data source, Share Price \& Price
Relative (SPPR) database of the Securities Industry Research Centre of Asia-Pacific (SIRCA). Overall, the results showed that the five-factor model was able to explain more asset pricing anomalies than other competing asset pricing models, but still had room for improvement [5]. Gregory et al established and measured the alternatives of the Fama-French model and Carhart model for the financial market in the UK. It formed risk factors, including value-weighted factor components and various decompositions comprehensively, and progressively with reference to the recent academic literature. Moreover, it found out whether such FamaFrench model applied to large-scale enterprises. Overall, the results demonstrate that such models were inappropriate and inaccurate to reflect the cross-section of returns in the UK [6]. Cakici, N. studied the fivefactor model in 23 developed stock markets. It referred to three factor, four factor and five factor models to explain the returns on different portfolios. The results showed that the five-factor model in North America, Europe, and Global markets resembled to that in the U.S. stock market. Furthermore, it was discovered that regional models were superior to global models, which indicated that markets were not sufficiently integrated. Two new factors, gross profitability (GP) and investment (Inv.), failed to add additional power but still remained important in the financial market [7]. Gregory et al analyzed the Fama-French and momentum portfolios for the financial market in UK. Different from other research, this paper investigates the market by forming portfolios methodically and systematically on an appropriate date in the UK. The data is cross-matched from two official database, then a UK proxy for the NYSE break points is found in order to form the portfolios and momentum factor based on website. Additionally, it cautiously takes portfolios on different bases into consideration. This research figures out that any tests of long run abnormal returns in UK ought to be based on characteristic-matched portfolios [8].

As for the effect of Covid-19, Zhang et al studied about the financial markets under the global pandemic of COVID-19. It mainly discussed about the significant impacts that COVID-19 brought to the global financial markets, and the substantial increases of volatility were found in global markets due to the outbreak. The global stock markets linkages displayed clear difference patterns before and after the pandemic announcement and future uncertainties that might be created by policy responses in the financial markets. The research compared different countries' stock market data since the coronavirus started. It also used graph theory and minimum spanning tree for the analysis. Overall, the results showed that global financial market risks had increased substantially because of the pandemic, the individual stock market reactions were clearly linked to the severity of the outbreak in each country, and the policy reactions to the virus were needed [9]. 
In this article, Fama-French five-factor model was adopted to study the changes in the U.S. stock market under the new crown epidemic. The Fama-French model is a relatively reliable asset pricing model and can be used in many fields. By testing several fields, it is found that Apparel industry is highly affected by the COVID19 epidemic. Therefore, it aims to investigate the effect of COVID-19 on the clothing industry based on the numeric analysis of the Fama-French five-factor model. The investigation will also provide relative investment examples of the clothing industry in the US stock market and explain the motivation for the investment change.

\section{METHOD}

The Capital Asset Pricing Model (CAPM) was developed by American scholars William Sharpe, John Lintner, Jack Treynor, and Jan Mossin in 1964. Developed on the basis of asset portfolio theory and capital market theory in 2015, it mainly studies the relationship between the expected rate of return of assets in the securities market and risky assets, and how the equilibrium price is formed. It is the backbone of modern financial market price theory and is widely used in investment decision-making and corporate financial management. But CAPM's interpretation of the financial market, in reality, is not good. Some long-term excess returns cannot be explained by CAMP. So there is the Fama-French three-factor model.

In the framework of classic financial theory, the risk of a single stock is broken down into individual risks and system risks. The so-called individual risk is the return and fluctuation of the asset itself. For example, the income and fluctuation of Apple's own business are good or bad. System risk is the return and volatility of the entire system, such as the return and volatility of the market.The classical financial theory attempts to describe system fluctuations with mathematical models and establish the relationship between the fluctuations of a single stock and the system fluctuations. For example, in the CAMP model, the description of system risk is the market portfolio.

$$
R_{i}=a_{i}+b_{i} R_{M}
$$

At the same time, it can also conclude that classic financial theory only uses random variables to describe the risks and returns of a single stock. In fact, the idea behind it is that the short-term fluctuations of a single stock are unpredictable (classic efficient market theory), but in the long run The volatility of the stock will eventually return to the volatility of the system. In other words, when a stock has excess returns, market arbitrageurs will appear to smooth out such excess returns. From another perspective, the existence of arbitrageurs corrects the mispricing of the market and makes profits at the same time, which is an essential part of the market. Classical financial theory has established a relational paradigm. What the arbitrageur has to do is to regress the relevant coefficients according to the data, and then analyze the arbitrage strategy according to the coefficients to obtain benefits. According to the analysis of system risk and individual risk, income can also be divided into income from the system and income from individuals. This is the so-called alpha income and beta income.

In a follow-up study of the CAPM model, Fama (1993) found that the market factor $\beta$ cannot explain $100 \%$ of the cross-sectional excess return of the portfolio. Therefore, Fama and French (1993) analyzed the influencing factors to better explain the excess return of the investment portfolio and proposed the FamaFrench three-factor model. The model believes that the factors in the capital asset pricing model cannot fully explain the excess returns of the stock portfolio. The size of the portfolio (represented by the market), the value and variable characteristics of the owner's equity $\mathrm{ME}$ (book-to-market value ratio $\mathrm{BE} / \mathrm{ME}$ ). The ai here is the unexplained excess return.

$$
R i=a i+b i R M+s i E(S M B)+h i E(H M I)+e i
$$

However, the model mentioned also meets the anomaly problem. In the past 20 years, many scholars have conducted empirical analysis on the three-factor model and found that the interception of some stocks is significantly non-zero, which indicates that the three risks (factors) in the three-factor model cannot explain all excess returns. Therefore, Fama and French introduce more factors, including profitability and investment factors to upgrade this issue, and its expression is as follows:

$R i=a i+b i R M+\operatorname{si} E(S M B)+h i E(H M I)+r i E(R M W)+c i E(C M A)+e i$

The five-factor model has two more than the threefactor model: $\mathrm{E}(\mathrm{RMW})$ is the return difference between high and low-profit stock portfolios, and E(CMA) is the low or high reinvestment ratio company The difference in the return of the stock portfolio. These two items describe the profit level risk and the investment level risk respectively (note that the investment level here is not the investment level of the secondary market, but can be easily explained as the enterprise's ability to expand reproduction). Similar to the three-factor model, the method of parameter estimation is still the method of multiple linear regression.

\section{RESULTS}

The data are selected from 38 Industry Portfolios in Kenneth R. French - Data Library, and we especially focused on two periods of time. Between the time when COVID-19 just started to spread hugely all over the world and after 9 months, we consider it as May 2019 to February 2020. Start from March 2020 and until the time when the first successful COVID-19 vaccine was 
reported on the news, and that is December 2020. MktRF, SMB, HML, RMW and, CMA are adopted as independent variables to conduct the regression and obtain the coefficients for Apparel.

TABLE 1. Results of Multi Regression From May 2019 to February 2020

\begin{tabular}{|c|c|c|c|c|}
\hline & Coefficients & $\begin{array}{c}\text { Standard } \\
\text { Error }\end{array}$ & T Stat & P-value \\
\hline Intercept & -0.020 & 0.048 & -0.410 & 0.682 \\
\hline Mkt-RF & 1.155 & 0.058 & 18.239 & 1.200 \\
\hline SMB & 0.155 & 0.108 & 1.441 & 0.151 \\
\hline HML & 0.067 & 0.111 & 0.604 & 0.547 \\
\hline RMW & 0.642 & 0.182 & 3.524 & 0.001 \\
\hline CMA & 0.020 & 0.214 & 0.092 & 0.927 \\
\hline
\end{tabular}

TABLE 2. Results of Multi Regression From March 2020 to December 2020

\begin{tabular}{|c|c|c|c|c|}
\hline & Coefficients & $\begin{array}{c}\text { Standard } \\
\text { Error }\end{array}$ & T Stat & $\begin{array}{c}\boldsymbol{P} \text { - } \\
\text { value }\end{array}$ \\
\hline Intercept & 0.005 & 0.088 & 0.061 & 0.951 \\
\hline Mkt-RF & 1.030 & 0.041 & 25.205 & 3.805 \\
\hline SMB & 0.405 & 0.105 & 3.847 & 0.001 \\
\hline HML & 0.342 & 0.087 & 3.945 & 0.001 \\
\hline RMW & 0.411 & 0.175 & 2.345 & 0.020 \\
\hline CMA & -0.495 & 0.224 & -2.204 & 0.029 \\
\hline
\end{tabular}

Table 1 is the result from May 2019 to February 2020 and Table 2 is the result from March 2020 to December 2020. It can see that the t-Stat value for SMB, HML, and CMA from May 2019 to February 2020 were 1.44, 0.60, and 0.09. However, after COVID-19 spread all over the world, the t-Stat value of these three factors become $3.84,3.94,-2.20$. Therefore, they become significant, which represents the change of investment trend.

\section{DISCUSSION}

\subsection{Mkt and RMW}

Mkt factor of the Apparel industry increases from 18.23 to 25.20 , and the coefficients are above 1 , which indicates this industry is more sensitive than the market in both periods. Throughout the pandemic, the Apparel industry has been hit as hard as other traditional industries. There is severe damage to the US economy caused by COVID-19. [10] Mentioned in The Business Research Company's research report on the apparel market, a survey was conducted in 2020 by McKinsey and company on 290 fashion executives to understand the state of the fashion industry in 2020. According to the survey, $57 \%, 58 \%$, and $58 \%$ of the fashion executives were of the view that the luxury fashion segment, midmarket, and value segments respectively will not see any growth in 2020 when compared to 2019, while $31 \%$, $39 \%$, and $38 \%$ of the fashion executives were of the view that the premium segment, mid-value segment, and value segment respectively will grow at a similar rate in 2020 as they did in 2019. This is reflected in the decrease in demand but a spur in online purchasing in the clothing market. The slowed-down economic activity due to COVID-19 across the globe has resulted in a decline in the apparel market demand. The apparel manufacturing industry is experiencing cuts in spending and poor consumer confidence due to fear of coronavirus spread. This low consumer demand keeps investors away from new investments in the sector. In addition, factors of RMW are both significant and positive, revealing that the companies with good profitability have more concentration from investors. According to the International Monetary Fund (IMF), global GDP will decline by $3 \%$ due to the COVID-19 impact. Many shop owners curbed their stock purchases due to low demand and increased inventory. According to the second survey report by the International Textile Manufacturers Federation (ITMF) between 28th March and 6th April, the global textile orders experienced around a $31 \%$ decline in orders in 2020. Fashion brands sales decreased by around $70 \%$ in India, owing to enforced lockdown and fear over coronavirus spread, which has piled up apparel inventory.

\section{2. $S M B$}

As illustrated in Table 1 and Table 2, SMB became significant and the coefficient is positive (0.405). This phenomenon proves that the Apparel industry is more inclined to small-scale enterprises during the COVID-19 epidemic. Due to the economic depression during COVID-19, investing in small-scale enterprises has a higher expected rate of return, which also requires investors to bear correspondingly higher risks and larger compensation for returns. Influenced by the new coronavirus pandemic in 2020, the global economy has been hit severely. The COVID-19 pandemic has also taken a heavy toll on the Apparel industry. Nevertheless, compared with the large-scale enterprises, small-scale enterprises are less affected by the outbreak of COVID19 , thus giving rise to a lower level of economic loss and financial deficit. Moreover, companies with a small-scale tend to possess superior opportunities to recover and revive their development mode. Therefore, investors are more willing to select small-scale enterprises when taking the economic influence of COVID-19 into consideration. As illustrated by Gregory, because of liquidity constraints and limits to stock availability in small-scale firms, people are reluctant to invest in small enterprises in the general case. Nevertheless, under the grim hit during COVID-19, small-scale companies suffered less economic loss, which allured numerous investors. For instance, large-scale enterprises like Amazon and Facebook lowered the expected return of advertisement to a great extent. Similarly, large catering enterprises like McDonald's close chain stores' in remote areas. The media industry also experienced a sharp decrease in profit gains. Although no sectors in the 
Apparel industry are left unaffected by COVID-19, investors are more inclined to opt for small-scale enterprises in a bid to reap more profits. The prosperity of these companies with small-scale has changed the way how investors consider the Apparel industry. Besides, under the promotion of favorable government policies in various countries, investors are more willing to invest in small-scale enterprises to gain a higher rate of return despite the potential instability and high risk.

\section{3. $H M L$}

Comparing Table 1 and Table 2, it is shown that the $\mathrm{t}$ Stat of HML increased from 0.604 to 3.945 . The coefficient of this factor is positive(0.342), which indicates that investors preferred to buy value stocks than growth stocks after the pandemic. Value stock refers to companies that are trading below what they really worth, their ratio of book value to market value is higher, which means they are relatively mature. Growth stocks, however, consider as companies that have future potential. Therefore, value stocks companies are normally more experienced and mature, which means that they are less risky compare to the growth stock. This is one of the important reasons why stock traders switch to invest in value stocks after the spreading of COVID19. It can conclude that after the pandemic, Apparel companies like Topshop and New Look got a huge financial crush that they have to close almost $40 \%$ of their offline shops to a minimum their costs. Whereas companies' stocks like Louis Vuitton and Hermès go up to the highest in past 5 years. Stock traders believed that mature companies could survive from this COVID-19 situation because they are more experienced, more reliable, and have more stable operating. Also, because of the pandemic, the U.S. government provided a huge subsidy to the society, which caused the inflation rate to go up. What's more, after the successful vaccine came out, many countries start to cancel the lockdown gradually. As people's life get back to normal, a huge amount of people will go shopping, therefore there is more cash coming into the market in a short period of time. This is another reason why the inflation rate went up. Therefore, more people would invest in value stock to keep their money value.

\subsection{CMA}

During the COVID 19 epidemic, aggressive investments pay off better. The world is still in the period of the new crown pneumonia epidemic, and there is no sign of easing. The economic prospects are also helpless, making many companies difficult and even leading to a wave of bankruptcy. But this is a favorable opportunity for corporate mergers and acquisitions, which is a competitive and capital reserve. For leading companies, take advantage of the current economic depression to win rivals or upstream and downstream related companies at a much cheaper price than before. The coefficient of CMA changed after the pandemic, which is also a direct reflection of the fervor trend of investors put money on an aggressive investment. During the COVID 19 epidemic, aggressive investments pay off better. The world is still in the period of the new crown pneumonia epidemic, and there is no sign of easing. The economic prospects are also helpless, making many companies difficult and even leading to a wave of bankruptcy. But this is a favorable opportunity for corporate mergers and acquisitions, which is a competitive and capital reserve. For leading companies, take advantage of the current economic depression to win rivals or upstream and downstream related companies at a much cheaper price than before.

On 2021 January 7, US Eastern time, Tiffany issued an announcement stating that LVMH has officially completed its acquisition. However, the transaction price was adjusted from the $\$ 135$ per share and the total cash price of $\$ 16.2$ billion determined in November last year to $\$ 131.5$ per share, a decrease of $\$ 3.5$ per share from the original purchase price, and the total transaction price fell to $\$ 15.8$ billion. Under the influence of the new crown epidemic, the sales of luxury brands have been hit hard this year. According to Tiffany's previously announced performance report, Tiffany's net sales fell $45 \%$ year-onyear to US\$556 million in the first quarter of the 2020 fiscal year as of April 30, with a net loss of US\$64.6 million; In the second quarter within three months, Tiffany's net sales fell $29 \%$ from the same period last year to 747 million US dollars, and the net profit was 32 million US dollars. In November 2019, LVMH announced that it would acquire Tiffany at a price of US\$135 per share, for a total price of approximately US\$16.2 billion. LVMH said that this acquisition aims to improve the group's position in the jewelry industry, while further enhancing its market share in the United States. But in September 2020, LVMH suddenly announced that it would not be able to complete the acquisition of Tiffany. The reason was that the United States announced in July that it would impose a $25 \%$ tariff on cosmetics and other goods imported from France. LVMH needs to change the acquisition date. put off. Considering the impact of the epidemic and other factors, the originally agreed Tiffany purchase price has been too high. This is the core reason for LVMH's abandonment. When the purchase price of Tiffany deviated from LVMH's initial estimate of $\$ 135$ per share, LVMH was eligible to lower the price. Finally, LVMH bought Tiffany at a low price.

\section{CONCLUSION}

Fama-French model investigates the influencing factors to explain the expected rate of return of the investment portfolios. In 2020, the global economy 
experienced tremendous depression because of the influence of COVID-19. This article evaluates the performance of Apparel industry during COVID-19 pandemic roundly and comprehensively. As shown in Table 1, the factors, SMB, HML and CMA, are insignificant before the COVID-19, but these three factors turn out to be significant after the outbreak. The results of this research demonstrate that investors are more optimistic and confident about the value stock in small enterprises. Companies with high book-to-market ratio can arouse a greater number of investors. Furthermore, during the epidemic, investors are more inclined to trust in companies with aggressive investing style, which are more probably to gain superior earnings. The results provide references for investors when choosing appropriate investing portfolios, such as the Black Swan Theory.

\section{REFERENCES}

[1] Chiah, M., Chai, D., Zhong, A., \& Li, S. (2015). A better model? an empirical investigation of the fama-french five-factor model in australia. International Review of Finance, 16(4), 595-638.

[2] Faff, R. (2004). A simple test of the fama and french model using daily data: australian evidence. Applied Financial Economics, 14(2), 83-92.

[3] Connor, G., \& Sehgal, S. (2001). Tests of the Fama and French model in India.
[4] Trimech, A., Kortas, H., Benammou, S., \& Benammou, S. (2009). Multiscale Fama-French model: application to the French market. The Journal of Risk Finance.

[5] Czapkiewicz, A., \& Skalna, I. (2010). The CAPM and Fama-French Models in Poland. Przegląd Statystyczny, 57(4), 128-141.

[6] Gregory, A., Tharyan R. \& Christidis A. (2011). Constructing and Testing Alternative Versions of the Fama-French and Carhart Models in the UK. 11(2).

[7] Cakici, N. (2015). The Five-Factor Fama-French Model: International Evidence.

[8] Gregory, A., haryan R. \& Huang A. (2009). The Fama-French and Momentum Portfolios and Factors in the UK. 9(5).

[9] Zhang, D., Hu, M., \& Ji, Q. (2020). Financial markets under the global pandemic of covid-19. Finance Research Letters, 101528.

[10] The business research company https://www.globenewswire.com/newsrelease/2021/01/05/2153683/0/en/COVID-19-HadA-Mixed-Impact-On-The-Apparel-Market-WithDemand-Decreasing-But-Online-PurchasingIncreasing.html 